\title{
Modeling and Dynamic Analysis of Cutterhead Driving System in Tunnel Boring Machine
}

\author{
Wei Sun, Honghui Ma, Xueguan Song, Lintao Wang, and Xin Ding \\ School of Mechanical Engineering, Dalian University of Technology, Dalian 116024, China \\ Correspondence should be addressed to Lintao Wang; wlt@dlut.edu.cn
}

Received 12 June 2016; Accepted 29 November 2016; Published 9 January 2017

Academic Editor: Evgeny Petrov

Copyright ( 2017 Wei Sun et al. This is an open access article distributed under the Creative Commons Attribution License, which permits unrestricted use, distribution, and reproduction in any medium, provided the original work is properly cited.

\begin{abstract}
Failure of cutterhead driving system (CDS) of tunnel boring machine (TBM) often occurs under shock and vibration conditions. To investigate the dynamic characteristics and reduce system vibration further, an electromechanical coupling model of CDS is established which includes the model of direct torque control (DTC) system for three-phase asynchronous motor and purely torsional dynamic model of multistage gear transmission system. The proposed DTC model can provide driving torque just as the practical inverter motor operates so that the influence of motor operating behavior will not be erroneously estimated. Moreover, nonlinear gear meshing factors, such as time-variant mesh stiffness and transmission error, are involved in the dynamic model. Based on the established nonlinear model of CDS, vibration modes can be classified into three types, that is, rigid motion mode, rotational vibration mode, and planet vibration mode. Moreover, dynamic responses under actual driving torque and idealized equivalent torque are compared, which reveals that the ripple of actual driving torque would aggravate vibration of gear transmission system. Influence index of torque ripple is proposed to show that vibration of system increases with torque ripple. This study provides useful guideline for antivibration design and motor control of CDS in TBM.
\end{abstract}

\section{Introduction}

Tunnel boring machine (TBM) is a large and high-tech construction equipment which is widely used in transport, municipal, and water diversion projects due to its advantages such as highly integrated functions, high tunneling speed, and environment-friendly construction [1]. Cutterhead is a key component of TBM, which can crush and cut rock with disc cutters mounted on its panel. As shown in Figure 1, cutterhead driving system (CDS) is a complex electromechanical coupling system, which is mainly composed of inverter motor, planetary reducer, pinion, and ring gear.

During tunneling process, driving torque provided by multiple inverter motor is transported from planetary reducer and pinions to ring gear, which is fixedly connected with cutterhead. Under the enlarged driving torque, cutterhead rotates and breaks rock. In CDS, variable frequency speed control system such as vector control (VC) and direct torque control (DTC) system are often applied to make inverter motor respond quickly to the variable load.

Due to complex and changing geological conditions, cutterhead and its driving system often suffer large impact load with drastic fluctuation during tunnel construction [2]. In addition, the multistage gear transmission system is a time varying and strong coupling system which causes periodic internal excitation owning to the nonlinear factors such as time-variant mesh stiffness, transmission error, and backlash [3]. Under such internal excitation formed in gear transmission system and external excitation caused by geological condition and inverter motor, server vibration in CDS often occurs and results in failures such as excessive wear, breakage of gear tooth and shaft, imbalance of driving torque, and so on [4]. To resolve these problems and improve the design of CDS, the dynamic characteristics of gear transmission system and the operating characters of inverter motor ought to be investigated primarily and imperatively. 


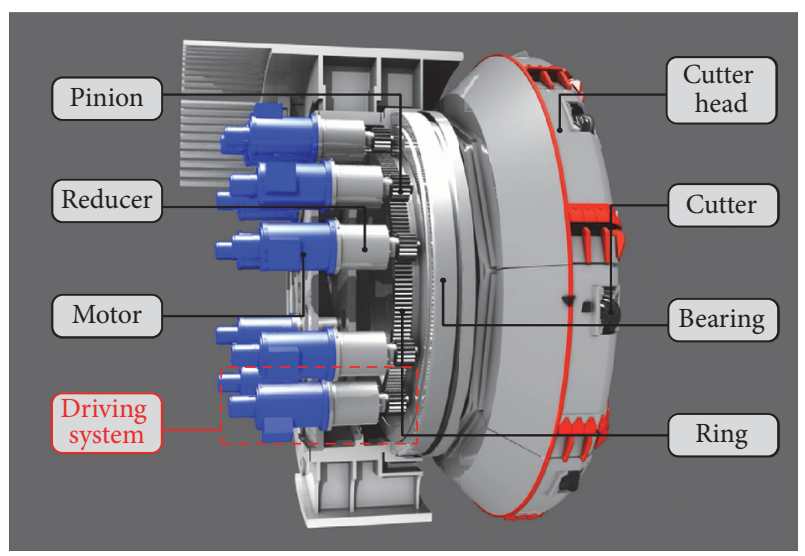

FIGURE 1: Cutterhead driving system in TBM.

In recent years, a large amount of work has been done on load sharing and vibration reduction of CDS in TBM. Numerous researches have focused on dynamic analysis of CDS. Wei et al. established a dynamic model of multigear driving system and studied the effects of inertia on loadsharing characteristic $[5,6]$. Sun et al. established a dynamic model of cutterhead driving system based on hierarchical modeling method and obtained dynamic response [7]. Zhang et al. analyzed dynamic characteristic of TBM in mixedface conditions [8]. Qin and Zhao built multiobjective optimization model based on dynamic analysis and optimized parameters of gear transmission system to reduce vibration [9]. Besides, multimotor synchronization control method of CDS also attracts more and more attentions. Liu et al. studied load-sharing characteristic of multiple motors and proposed an adaptable control approach to improve the compliance ability of CDS [10-12]. All these researches have made fruitful efforts on design of CDS through dynamic analysis and optimization of multimotor control strategy. However, these studies did not consider the influence of external excitation provided by inverter motor, which just replaced the actual driving torque with an idealized constant value. A number of researches have shown that torque ripple caused by variable frequency speed control system is an inevitable factor which may influence the dynamic performance of transmission mechanism [13]. Without considering the ripple of actual driving torque, dynamic analysis of gear transmission may be erroneously investigated. Therefore, it needs to take operating characters of inverter motor into account for building the electromechanical coupling model and studying the dynamic characteristic of multistage gear transmission system in CDS.

In this paper, dynamic analysis of CDS in TBM is studied to explore the failure reasons of key components. An electromechanical coupling model of CDS is established which includes a dynamic model of DTC driving system and a purely torsional dynamic model of multistage gear transmission system. By taking the nonlinear factors of gear meshing and the operating characters of inverter motor into account, dynamic characteristics of multistage gear transmission system under the actual driving torque are analyzed. It provides data support for gear antivibration design and motor control of CDS in TBM.

\section{Mathematical Modeling of TBM Cutterhead Driving System}

2.1. Dynamic Model of DTC Driving System. DTC system is particularly applied to CDS with large inertia which needs rapid torque response. Based on Bang-Bang control method, DTC system regulates stator flux and provides heavy starting torque for CDS.

In DTC driving system, $\alpha-\beta$ phase static coordinate system is chosen as the reference frame of mathematical model of three-phase asynchronous motor, and hence the voltage equation can be expressed as follows:

$$
\begin{aligned}
& {\left[\begin{array}{c}
u_{s \alpha} \\
u_{s \beta} \\
0 \\
0
\end{array}\right]} \\
& =\left[\begin{array}{cccc}
R_{s}+p L_{s} & 0 & p L_{m} & 0 \\
0 & R_{s}+p L_{s} & 0 & p L_{m} \\
p L_{m} & L_{s} \omega & R_{r}+p L_{r} & L_{r} \omega \\
-\omega L_{m} & p L_{m} & -\omega L_{r} & R_{r}+p L_{r}
\end{array}\right]\left[\begin{array}{c}
i_{s \alpha} \\
i_{s \beta} \\
i_{r \alpha} \\
i_{r \beta}
\end{array}\right]
\end{aligned}
$$

Flux Equation

$$
\left[\begin{array}{c}
\psi_{s \alpha} \\
\psi_{s \beta} \\
\psi_{r \alpha} \\
\psi_{r \beta}
\end{array}\right]=\left[\begin{array}{cccc}
L_{s} & 0 & L_{m} & 0 \\
0 & L_{s} & 0 & L_{m} \\
L_{m} & 0 & L_{r} & 0 \\
0 & L_{m} & 0 & L_{r}
\end{array}\right]\left[\begin{array}{c}
i_{s \alpha} \\
i_{s \beta} \\
i_{r \alpha} \\
i_{r \beta}
\end{array}\right]
$$

Torque Equation

$$
\begin{aligned}
T_{e} & =n_{p} L_{m}\left(i_{s \beta} i_{r \alpha}-i_{r \beta} i_{s \alpha}\right)=n_{p}\left(i_{s \beta} \psi_{s \alpha}-i_{s \alpha} \psi_{s \beta}\right) \\
& =n_{p}\left(\psi_{s} \otimes i_{s}\right),
\end{aligned}
$$

where $u_{s \alpha}$ and $u_{s \beta}$ are stator voltages; $i_{s \alpha}, i_{s \beta}, i_{r \alpha}$, and $i_{r \beta}$ are stator/rotor currents; $\psi_{s \alpha}, \psi_{s \beta}, \psi_{r \alpha}$, and $\psi_{r \beta}$ are stator/rotor fluxes; $R_{s}$ and $R_{r}$ are stator/rotor resistances; $R_{s}$ and $R_{r}$ are stator/rotor resistances; $L_{s}, L_{r}$, and $L_{m}$ are stator/rotor inductance and mutual inductance; $T_{e}$ is electromagnet torque; $\omega$ is electrical angular speed of rotor; $n_{p}$ is the number of pole pairs; and $p$ is differential operator.

On the basis of (1)-(3), DTC system of CDS is established by Simulink module in Matlab software as shown in Figure 2. The $u$ - $i$ model is chosen as the stator flux observer which can be expressed as follows:

$$
\begin{aligned}
& \psi_{s \alpha}=\int\left(u_{s \alpha}-R_{s} i_{s \alpha}\right) d t \\
& \psi_{s \beta}=\int\left(u_{s \beta}-R_{s} i_{s \beta}\right) d t .
\end{aligned}
$$




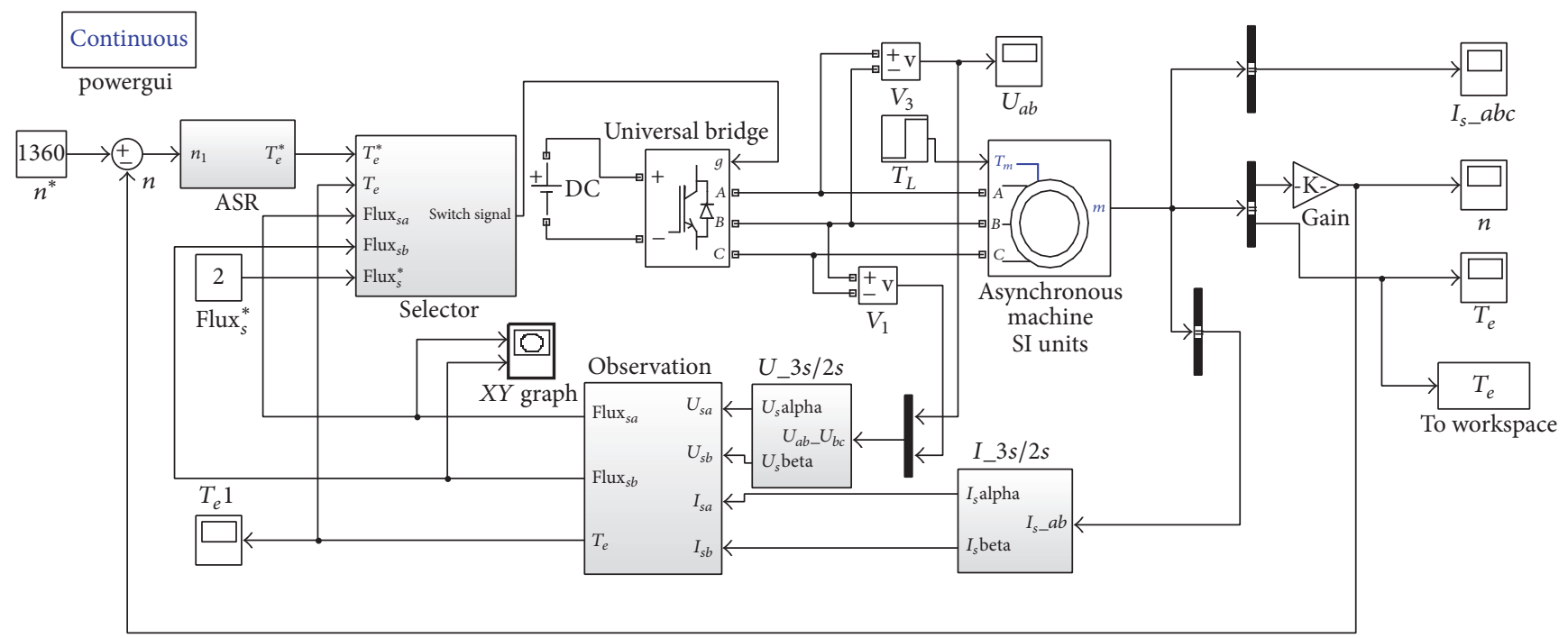

FIGURE 2: Direct torque control system of three-phase asynchronous motor.

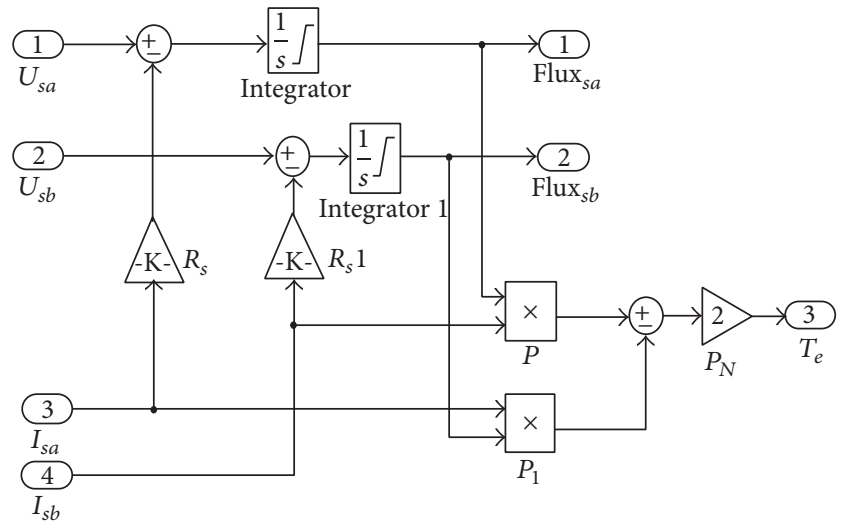

Figure 3: Torque and stator flux observer model.

According to (3)-(4), torque and stator flux observer model is established as shown in Figure 3. In DTC system, the amplitude of stator flux $\psi_{s}$ is kept constant and the angle of stator flux $\psi_{s}$ is regulated to control the electromagnet torque as shown in Figure 4. The asynchronous motor is controlled by switch status of voltage space vector in inverter. Driving signals are selected from the optimal switching table after directly calculating stator flux and torque. The location of stator flux in $\alpha$ - $\beta$ phase static coordinate system can be calculated by comparing the observed values of $\psi_{s}$ and $T_{e}$ with the given value of $\psi_{s}^{*}$ and $T_{e}^{*}$.

Based on the model of DTC driving system, frequency control process of inverter motor can be simulated and electromagnet torque $T_{e}$ can be obtained to drive the multistage gear transmission system.

2.2. Dynamic Model of Multistage Gear Transmission System. As shown in Figure 5, multistage gear transmission system

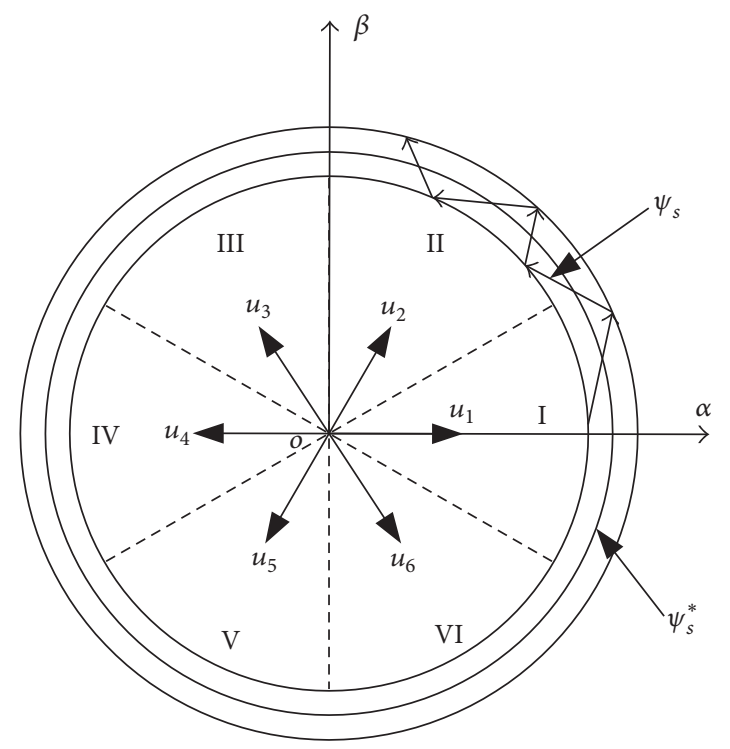

FIGURE 4: Control principle of DTC system.

is composed of three-stage planetary reducer and one-stage pinion-ring gears. $s^{(i)}, r^{(i)}, c^{(i)}$, and $p_{j}^{(i)}(i=1,2,3 ; j=$ $1,2,3,4)$ represent the $i$ th-stage sun gear, ring gear, planet carrier, and the $i$ th-stage, $j$ th planet gear in planetary reducer. $g_{1}$ and $g_{2}$ represent pinion-ring gears.

Based on the lumped mass method, a purely torsional dynamic model of multistage gear transmission system is established. Each component is regarded as a rigid body. The direction of displacement along the meshing line is supposed to be positive when the tooth surface is under pressure. Based on Newton's Second Law, the equivalent mathematic model of 


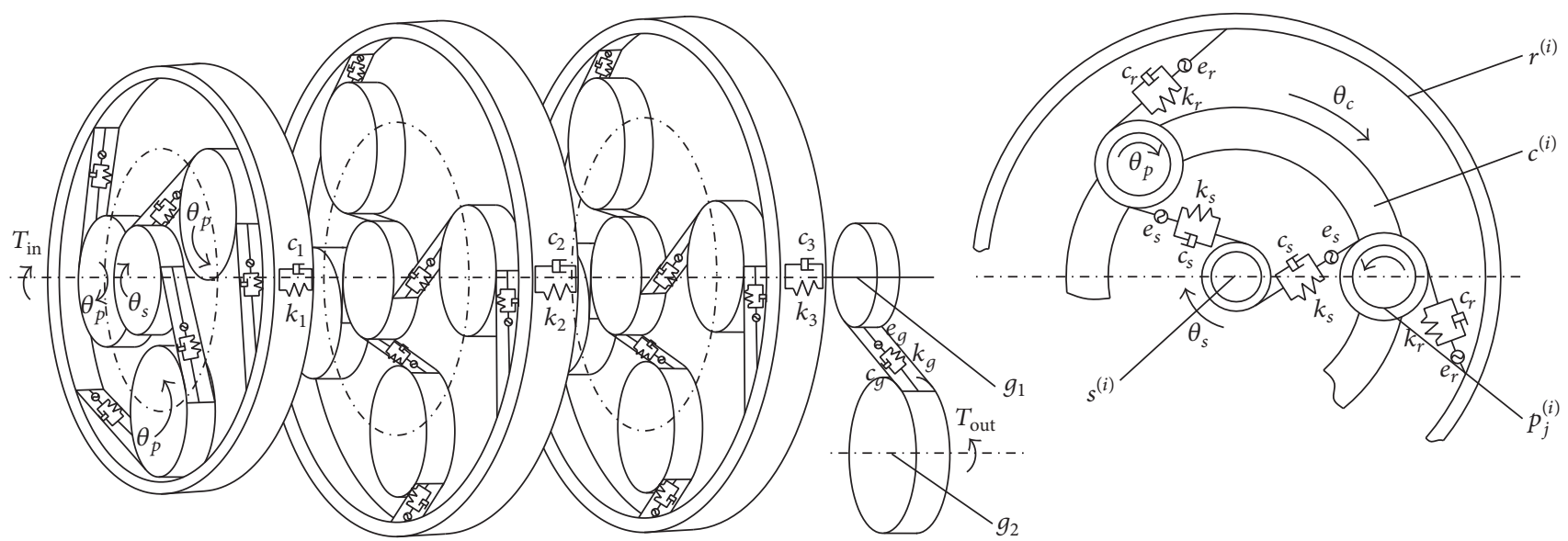

FIGURE 5: Purely torsional dynamic model of multistage gear transmission system.

the multistage gear transmission system can be expressed as follows:

$$
\begin{aligned}
& I_{s}^{(1)} \ddot{\theta}_{s}^{(1)}=T_{\mathrm{in}}-\sum_{j=1}^{3} k_{s j}^{(1)} x_{s j}^{(1)} r_{s}^{(1)}-\sum_{j=1}^{3} c_{s j}^{(1)} \dot{x}_{s j}^{(1)} r_{s}^{(1)} \\
& I_{p 1}^{(1)} \ddot{\theta}_{p 1}^{(1)}=k_{s 1}^{(1)} x_{s 1}^{(1)} r_{p 1}^{(1)}-k_{r 1}^{(1)} x_{r 1}^{(1)} r_{p 1}^{(1)}+c_{s 1}^{(1)} \dot{x}_{s 1}^{(1)} r_{p 1}^{(1)} \\
& -c_{r 1}^{(1)} \dot{x}_{r 1}^{(1)} r_{p 1}^{(1)} \\
& I_{p 2}^{(1)} \ddot{\theta}_{p 2}^{(1)}=k_{s 2}^{(1)} x_{s 2}^{(1)} r_{p 2}^{(1)}-k_{r 2}^{(1)} x_{r 2}^{(1)} r_{p 2}^{(1)}+c_{s 2}^{(1)} \dot{x}_{s 2}^{(1)} r_{p 2}^{(1)} \\
& -c_{r 2}^{(1)} \dot{x}_{r 2}^{(1)} r_{p 2}^{(1)} \\
& I_{p 3}^{(1)} \ddot{\theta}_{p 3}^{(1)}=k_{s 3}^{(1)} x_{s 3}^{(1)} r_{p 3}^{(1)}-k_{r 3}^{(1)} x_{r 3}^{(1)} r_{p 3}^{(1)}+c_{s 3}^{(1)} \dot{x}_{s 3}^{(1)} r_{p 3}^{(1)} \\
& -c_{r 3}^{(1)} \dot{x}_{r 3}^{(1)} r_{p 3}^{(1)} \\
& I_{c}^{(1)} \ddot{\theta}_{c}^{(1)}=\sum_{j=1}^{3}\left[\left(k_{s j}^{(1)} x_{s j}^{(1)}+k_{r j}^{(1)} x_{r j}^{(1)}\right) r_{c}^{(1)} \cos \alpha\right] \\
& +\sum_{j=1}^{3}\left[\left(c_{s j}^{(1)} \dot{x}_{s j}^{(1)}+c_{r j}^{(1)} \dot{x}_{r j}^{(1)}\right) r_{c}^{(1)} \cos \alpha\right]-k_{c}^{(1)} \theta_{c}^{(1)} \\
& -c_{c}^{(1)} \dot{\theta}_{c}^{(1)}-k_{1}\left(\theta_{c}^{(1)}-\theta_{s}^{(2)}\right)-c_{1}\left(\dot{\theta}_{c}^{(1)}-\dot{\theta}_{s}^{(2)}\right) \\
& I_{s}^{(2)} \ddot{\theta}_{s}^{(2)}=k_{1}\left(\theta_{c}^{(1)}-\theta_{s}^{(2)}\right)+c_{1}\left(\dot{\theta}_{c}^{(1)}-\dot{\theta}_{s}^{(2)}\right) \\
& -\sum_{j=1}^{4} k_{s j}^{(2)} x_{s j}^{(2)} r_{s}^{(2)}-\sum_{j=1}^{4} c_{s j}^{(2)} \dot{x}_{s j}^{(2)} r_{s}^{(2)} \\
& I_{p 1}^{(2)} \ddot{\theta}_{p 1}^{(2)}=k_{s 1}^{(2)} x_{s 1}^{(2)} r_{p 1}^{(2)}-k_{r 1}^{(2)} x_{r 1}^{(2)} r_{p 1}^{(2)}+c_{s 1}^{(2)} \dot{x}_{s 1}^{(2)} r_{p 1}^{(2)} \\
& -c_{r 1}^{(2)} \dot{x}_{r 1}^{(2)} r_{p 1}^{(2)}
\end{aligned}
$$

$$
\begin{aligned}
& I_{p 2}^{(2)} \ddot{\theta}_{p 2}^{(2)}=k_{s 2}^{(2)} x_{s 2}^{(2)} r_{p 2}^{(2)}-k_{r 2}^{(2)} x_{r 2}^{(2)} r_{p 2}^{(2)}+c_{s 2}^{(2)} \dot{x}_{s 2}^{(2)} r_{p 2}^{(2)} \\
& -c_{r 2}^{(2)} \dot{x}_{r 2}^{(2)} r_{p 2}^{(2)} \\
& I_{p 3}^{(2)} \ddot{\theta}_{p 3}^{(2)}=k_{s 3}^{(2)} x_{s 3}^{(2)} r_{p 3}^{(2)}-k_{r 3}^{(2)} x_{r 3}^{(2)} r_{p 3}^{(2)}+c_{s 3}^{(2)} \dot{x}_{s 3}^{(2)} r_{p 3}^{(2)} \\
& -c_{r 3}^{(2)} \dot{x}_{r 3}^{(2)} r_{p 3}^{(2)} \\
& I_{p 4}^{(2)} \ddot{\theta}_{p 4}^{(2)}=k_{s 4}^{(2)} x_{s 4}^{(2)} r_{p 4}^{(2)}-k_{r 4}^{(2)} x_{r 4}^{(2)} r_{p 4}^{(2)}+c_{s 4}^{(2)} \dot{x}_{s 4}^{(2)} r_{p 4}^{(2)} \\
& -c_{r 4}^{(2)} \dot{x}_{r 4}^{(2)} r_{p 4}^{(2)} \\
& I_{c}^{(2)} \ddot{\theta}_{c}^{(2)}=\sum_{j=1}^{4}\left[\left(k_{s j}^{(2)} x_{s j}^{(2)}+k_{r j}^{(2)} x_{r j}^{(2)}\right) r_{c}^{(2)} \cos \alpha\right] \\
& +\sum_{j=1}^{4}\left[\left(c_{s j}^{(2)} \dot{x}_{s j}^{(2)}+c_{r j}^{(2)} \dot{x}_{r j}^{(2)}\right) r_{c}^{(2)} \cos \alpha\right]-k_{c}^{(2)} \theta_{c}^{(2)} \\
& -c_{c}^{(2)} \dot{\theta}_{c}^{(2)}-k_{2}\left(\theta_{c}^{(2)}-\theta_{s}^{(3)}\right)-c_{2}\left(\dot{\theta}_{c}^{(2)}-\dot{\theta}_{s}^{(3)}\right) \\
& I_{s}^{(3)} \ddot{\theta}_{s}^{(3)}=k_{2}\left(\theta_{c}^{(2)}-\theta_{s}^{(3)}\right)+c_{2}\left(\dot{\theta}_{c}^{(2)}-\dot{\theta}_{s}^{(3)}\right) \\
& -\sum_{j=1}^{4} k_{s j}^{(3)} x_{s j}^{(3)} r_{s}^{(3)}-\sum_{j=1}^{4} c_{s j}^{(3)} \dot{x}_{s j}^{(3)} r_{s}^{(3)} \\
& I_{p 1}^{(3)} \ddot{\theta}_{p 1}^{(3)}=k_{s 1}^{(3)} x_{s 1}^{(3)} r_{p 1}^{(3)}-k_{r 1}^{(3)} x_{r 1}^{(3)} r_{p 1}^{(3)}+c_{s 1}^{(3)} \dot{x}_{s 1}^{(3)} r_{p 1}^{(3)} \\
& -c_{r 1}^{(3)} \dot{x}_{r 1}^{(3)} r_{p 1}^{(3)} \\
& I_{p 2}^{(3)} \ddot{\theta}_{p 2}^{(3)}=k_{s 2}^{(3)} x_{s 2}^{(3)} r_{p 2}^{(3)}-k_{r 2}^{(3)} x_{r 2}^{(3)} r_{p 2}^{(3)}+c_{s 2}^{(3)} \dot{x}_{s 2}^{(3)} r_{p 2}^{(3)} \\
& -c_{r 2}^{(3)} \dot{x}_{r 2}^{(3)} r_{p 2}^{(3)}
\end{aligned}
$$




$$
\begin{aligned}
& I_{p 3}^{(3)} \ddot{\theta}_{p 3}^{(3)}=k_{s 3}^{(3)} x_{s 3}^{(3)} r_{p 3}^{(3)}-k_{r 3}^{(3)} x_{r 3}^{(3)} r_{p 3}^{(3)}+c_{s 3}^{(3)} \dot{x}_{s 3}^{(3)} r_{p 3}^{(3)} \\
& -c_{r 3}^{(3)} \dot{x}_{r 3}^{(3)} r_{p 3}^{(3)} \\
& I_{p 4}^{(3)} \ddot{\theta}_{p 4}^{(3)}=k_{s 4}^{(3)} x_{s 4}^{(3)} r_{p 4}^{(3)}-k_{r 4}^{(3)} x_{r 4}^{(3)} r_{p 4}^{(3)}+c_{s 4}^{(3)} \dot{x}_{s 4}^{(3)} r_{p 4}^{(3)} \\
& -c_{r 4}^{(3)} \dot{x}_{r 4}^{(3)} r_{p 4}^{(3)} \\
& I_{c}^{(3)} \ddot{\theta}_{c}^{(3)}=\sum_{j=1}^{4}\left[\left(k_{s j}^{(3)} x_{s j}^{(3)}+k_{r j}^{(3)} x_{r j}^{(3)}\right) r_{c}^{(3)} \cos \alpha\right] \\
& \quad+\sum_{j=1}^{4}\left[\left(c_{s j}^{(3)} \dot{x}_{s j}^{(3)}+c_{r j}^{(3)} \dot{x}_{r j}^{(3)}\right) r_{c}^{(3)} \cos \alpha\right]-k_{c}^{(3)} \theta_{c}^{(3)} \\
& -c_{c}^{(3)} \dot{\theta}_{c}^{(3)}-k_{3}\left(\theta_{c}^{(3)}-\theta_{g 1}\right)-c_{3}\left(\dot{\theta}_{c}^{(3)}-\dot{\theta}_{g 1}\right) \\
& I_{g 1} \ddot{\theta}_{g 1}=k_{3}\left(\theta_{c}^{(3)}-\theta_{g 1}\right)+c_{3}\left(\dot{\theta}_{c}^{(3)}-\dot{\theta}_{g 1}\right)-k_{g}\left(r_{g 1} \theta_{g 1}\right. \\
& \left.\quad-r_{g 2} \theta_{g 2}+e_{g}\right)-c_{g}\left(r_{g 1} \dot{\theta}_{g 1}-r_{g 2} \dot{\theta}_{g 2}+\dot{e}_{g}\right) \\
& I_{g 2} \ddot{\theta}_{g 2}=n\left[k_{g}\left(r_{g 1} \theta_{g 1}-r_{g 2} \theta_{g 2}+e_{g}\right)\right. \\
& \left.\quad+c_{g}\left(r_{g 1} \dot{\theta}_{g 1}-r_{g 2} \dot{\theta}_{g 2}+\dot{e}_{g}\right)\right]-T_{\text {out }},
\end{aligned}
$$

where $I_{s}, I_{p}, I_{c}, I_{g 1}$, and $I_{g 2}$ are mass moments of inertia of sun gear, planet gear, planet carrier in reducer, and pinionring gears; $r_{s}, r_{p}, r_{c}, r_{g 1}$, and $r_{g 2}$ are base radiuses of sun gear, planet gear, planet carrier in reducer, and pinion-ring gears; $\theta_{s}, \theta_{p}, \theta_{c}, \theta_{g 1}$, and $\theta_{g 2}$ are angular displacements of sun gear, planet gear, planet carrier in reducer, and pinionring gears; $T_{\text {in }}$ is driving torque of inverter motor which is equal to electromagnet torque $T_{e}$ in DTC system; $T_{\text {out }}$ is the enlarged driving torque by gear transmission system; $k_{c}$ is torsional stiffness of planet carrier; $k_{1}, k_{2}$, and $k_{3}$ are torsional stiffnesses of each stage connecting stage; $c_{c}$ is torsional damping of planet carrier; $c_{1}, c_{2}$, and $c_{3}$ are torsional dampings of each stage connecting stage; $\alpha$ is pressure angle at the pitch cylinder; $n$ is number of pinions; $x_{s}$ is displacement along the meshing line between the sun gear and each planet gear; and $x_{r}$ is displacement along the meshing line between the ring gear and each planet gear.

$x_{s}$ and $x_{r}$ can be expressed as follows:

$$
\begin{aligned}
& x_{s j}^{(i)}=r_{s}^{(i)} \theta_{s}^{(i)}-r_{p j}^{(i)} \theta_{p j}^{(i)}-r_{c}^{(i)} \theta_{c}^{(i)} \cos \alpha+e_{s j}^{(i)} \\
& x_{r j}^{(i)}=r_{p j}^{(i)} \theta_{p j}^{(i)}-r_{c}^{(i)} \theta_{c}^{(i)} \cos \alpha+e_{r j}^{(i)}
\end{aligned}
$$

$$
(i=1,2,3 ; j=1,2,3,4),
$$

where $e_{s}$ is transmission error between the sun gear and each planet gear and $e_{r}$ is transmission error between the ring gear and each planet gear.

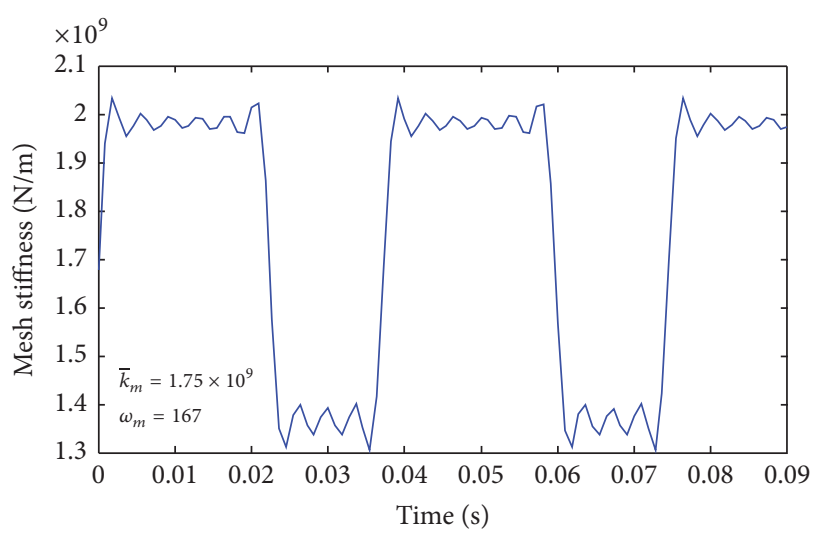

Figure 6: Time-varying mesh stiffness.

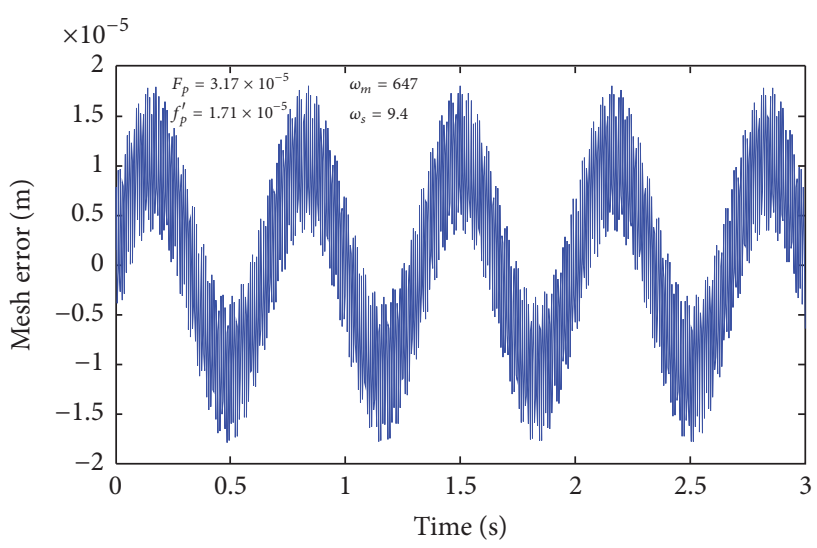

FiguRE 7: Transmission mesh error.

As shown in Figure $6, k_{s}, k_{r}$, and $k_{g}$ are time-variant mesh stiffnesses which can be expressed by means of the Fourier series expansion as follows [14]:

$$
k_{m}(t)=\bar{k}_{m}+\sum_{n=1}^{N} B_{n} \cos i \omega_{m}(t+\varphi) \quad m=s, r, g,
$$

where $\bar{k}_{m}$ is average mesh stiffness which can be obtained based on gear standards such as AGMA ISO 1328-1 and DIN3990 and $B_{n}$ is the $n$-rank harmonic amplitude in Fourier series.

$c_{s}, c_{r}$, and $c_{g}$ are mesh dampings which can be expressed as follows:

$$
c_{m}=2 \varsigma \sqrt{\frac{\bar{k}_{m} m_{m} m_{n}}{m_{m}+m_{n}}} \quad m \text { or } n=s, r, p, g,
$$

where $\varsigma$ is gear mesh damping ratio $(\varsigma=0.03-0.17)$ and $m_{m}$ and $m_{n}$ are masses of two meshing gears.

As shown in Figure 7, transmission error $e_{n}$ is approximated as superposition of harmonic function of mesh frequency and rotation frequency of shaft [15].

$$
\begin{array}{r}
e_{n}=0.5 F_{p} \sin \left(2 \pi \omega_{s} t+\varphi_{s}\right)+0.5 f_{p}^{\prime} \sin \left(2 \pi \omega_{m} t+\varphi_{m}\right) \\
n=s, r, g,
\end{array}
$$


TABLE 1: Technical parameters of TBM cutterhead driving system.

\begin{tabular}{lcc}
\hline \multirow{2}{*}{ Driving motor } & Rated power & $160 \mathrm{~kW}$ \\
& Speed range & $0-1480 \mathrm{rpm}$ \\
\hline \multirow{2}{*}{ Transmission system } & Reducer & Gear ratio, $i_{\mathrm{I}}=51.2$ \\
& Ring-pinion & Gear ratio, $i_{\mathrm{II}}=12.6$ \\
\hline \multirow{3}{*}{ Cutterhead } & Rated power & $1600 \mathrm{~kW}(10 * 160 \mathrm{~kW})$ \\
& Speed range & $0-2.1 \mathrm{rpm}-4.7 \mathrm{rpm}$ \\
& Rated torque & $7230 \mathrm{KNm} @ 2.1 \mathrm{rpm}$ \\
\hline
\end{tabular}

TABLE 2: Parameters of three-phase asynchronous motor.

\begin{tabular}{lc}
\hline Parameters & Value \\
\hline Rated power $P_{N}$ & $160 \mathrm{~kW}$ \\
Rated voltage $U_{N}$ & $400 \mathrm{~V}$ \\
Rated frequency $f_{N}$ & $50 \mathrm{~Hz}$ \\
Stator resistance $R_{s}$ & $0.01379 \Omega$ \\
Rotor resistance $R_{r}$ & $0.007728 \Omega$ \\
Stator inductance $L_{s}$ & $0.152 \mathrm{mH}$ \\
Rotor inductance $L_{r}$ & $0.152 \mathrm{mH}$ \\
Mutual inductance $L_{m}$ & $7.69 \mathrm{mH}$ \\
Rotational inertia $J$ & $2.9 \mathrm{~kg} \cdot \mathrm{m}^{2}$ \\
\hline
\end{tabular}

where $F_{p}$ is total cumulative pitch error; $f_{p}^{\prime}$ is tangential tolerance of single tooth; $\omega_{s}$ and $\omega_{m}$ are rotation frequency and mesh frequency; and $\varphi_{s}$ and $\varphi_{m}$ are initial phase of shaft and mesh phase.

\section{Dynamic Analysis of Electromechanical Coupling Model of CDS}

3.1. Actual Driving Torque of DTC System. The technical parameters of one certain CDS are shown in Table 1. According to these parameters, the model of three-phase asynchronous motor is chosen as Table 2 shows and the control parameters of DTC system are set. In this paper, the multiple inverter motors are supposed to be synchronous and TBM cutterhead is chosen to work under the rotational speed $n_{c}=2.1 \mathrm{rpm}$. Thus, load torque of motor can be calculated based on the mean value of load torque on cutterhead which can be expressed as (10) shows.

$$
T_{L}=9549 \frac{P_{N}}{i_{\mathrm{I}} i_{\mathrm{II}} n_{c} n},
$$

where $P_{N}$ is rated power; $i_{\mathrm{I}}$ is gear ratio of reducer; $i_{\mathrm{II}}$ is gear ratio of ring-pinion gears; $n_{c}$ is rated speed of cutterhead; and $n$ is number of pinions.

Field test data of external load torque is shown in Figure 9. In actual tunneling process, load torque $T_{L}$ is unstable and changes abruptly as geological condition varies. On the basis of (10), rated $T_{L}$ is $1120 \mathrm{~N} \cdot \mathrm{m}$ under rated rotational speed $n_{c}=2.1 \mathrm{rpm}$, which corresponds to the actual $T_{L}$ near $310 \mathrm{~s}$ in Figure 8. Thus, taking a $1 \mathrm{~s}$-length (of) actual $T_{L}$ between $314.2 \mathrm{~s}$ and $315.2 \mathrm{~s}$ as an example, $T_{L}$ in the first $0.2 \mathrm{~s}$ keeps stable near rated torque and then rises sharply to $1700 \mathrm{~N} \cdot \mathrm{m}$ at $314.4 \mathrm{~s}$. After $314.5 \mathrm{~s}, T_{L}$ remains roughly stable near $1700 \mathrm{~N} \cdot \mathrm{m}$

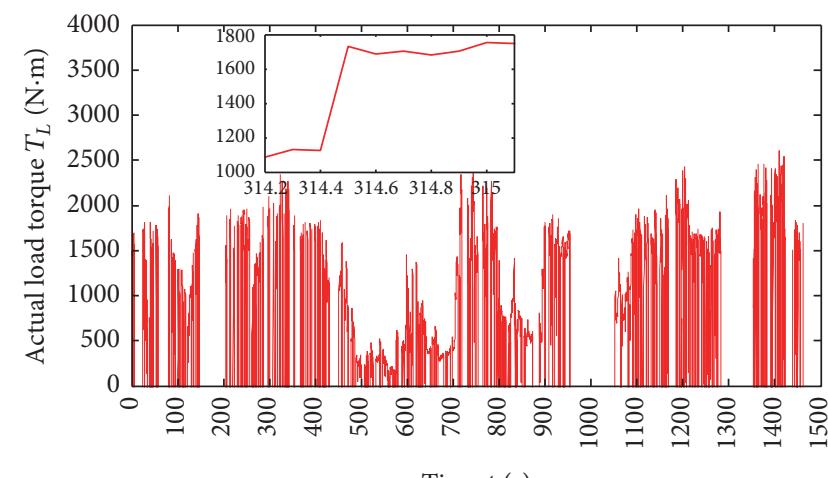

Time $t(\mathrm{~s})$

Figure 8: Field test data of external load torque.

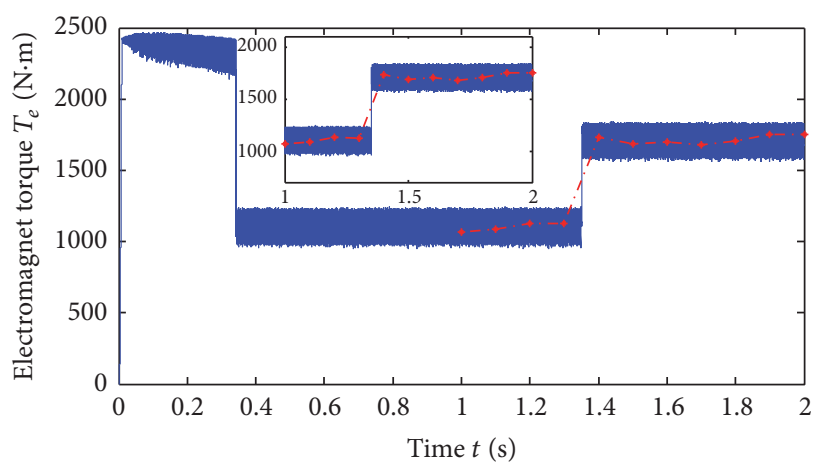

— DTC driving torque

$\rightarrow-$ Actual driving torque

Figure 9: Actual driving torque of DTC system.

with little fluctuations. To study the operating characters of inverter motor under shocking load, the $1 \mathrm{~s}$-length of $T_{L}$ between $314.2 \mathrm{~s}$ and $315.2 \mathrm{~s}$ is chosen to be simulated as a piecewise function. In DTC driving system, load torque $T_{L}$ is simulated for $2 \mathrm{~s} . T_{L}$ is set to be $1100 \mathrm{~N} \cdot \mathrm{m}$ before $1.35 \mathrm{~s}$ and $T_{L}$ is equal to $1700 \mathrm{~N} \cdot \mathrm{m}$ during $1.35 \mathrm{~s}$ and $2 \mathrm{~s}$.

The actual driving torque of DTC system is obtained and shown in Figure 9. In the start-up phase, inverter motor operates with the maximum torque to accelerate to the rated speed quickly. After operating for $1 \mathrm{~s}$, electromagnetic torque $T_{e}$ fits the actual load torque under rated speed. The fitting result shows that DTC driving system responds quickly according to the changing load torque $T_{L}$. However, electromagnetic torque $T_{e}$ has high torque ripple which is about $120 \mathrm{~N} \cdot \mathrm{m}$, which can be expressed in discrete form as follows [16]:

$$
\begin{aligned}
T_{e}^{(k+1)} & =T_{e}^{(k)}+\Delta T_{e 1}^{(k)}+\Delta T_{e 1}^{(k)} \\
\Delta T_{e 1}^{(k)} & =-T_{e}^{(k)}\left(\frac{R_{s}}{L_{s}}+\frac{R_{r}}{L_{r}}\right) \frac{T_{s}}{\sigma} \\
\Delta T_{e 2}^{(k)} & =\frac{3}{2} n_{p} \frac{L_{m}}{\sigma L_{s} L_{r}}\left[\left(u_{s}^{(k)}-j \omega_{r}^{(k)} \psi_{s}^{(k)}\right) \cdot j \psi_{r}^{(k)}\right] T_{s},
\end{aligned}
$$


TABLE 3: Parameters of 3-stage planetary reducer in TBM.

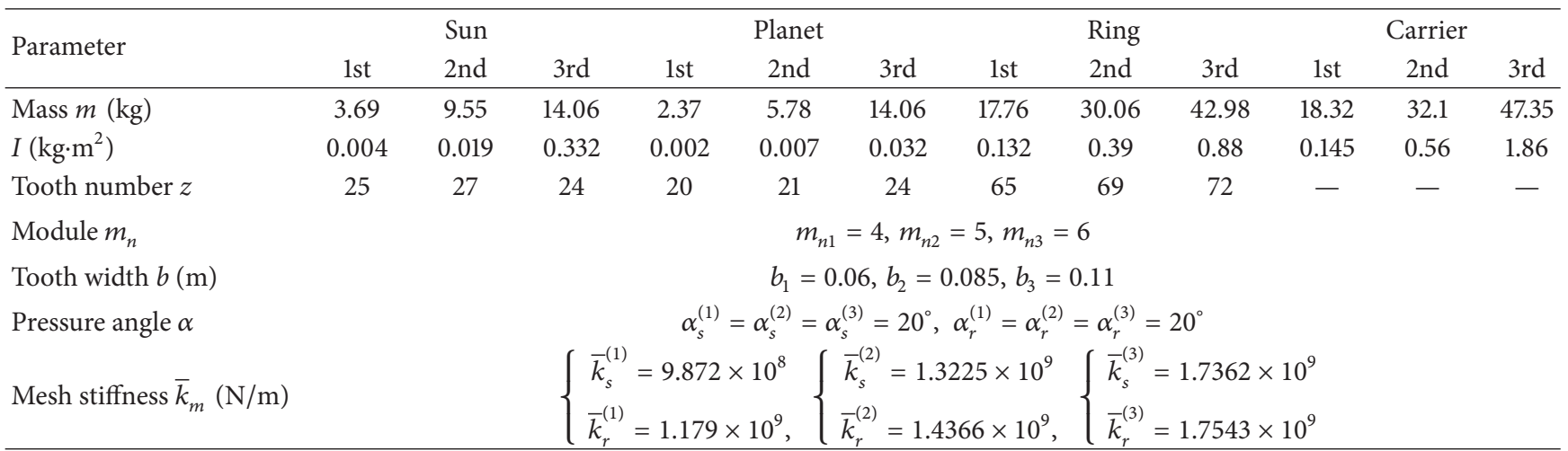

TABLE 4: Natural frequencies of planetary reducer.

\begin{tabular}{ll}
\hline Motion modes & Natural frequency $(\mathrm{Hz})$ \\
\hline Rigid motion mode & $f_{1}=0$ \\
Rotational vibration modes & $f_{2}=308 ; f_{3}=529 ; f_{4}=2806 ; f_{8}=3772 ; f_{9}=4644 ; f_{13}=5919 ; f_{16}=6798 ; f_{17}=8338$ \\
Planet vibration modes & $f_{5}=f_{6}=f_{7}=3598 ; f_{10}=f_{11}=f_{12}=4965 ; f_{14}=f_{15}=6655 ;$ \\
\hline
\end{tabular}

where $T_{e}^{(k+1)}$ and $T_{e}^{(k)}$ are electromagnetic torques at $k+1$ and $k$ moment; $\Delta T_{e 1}^{(k)}$ is torque attenuation caused by stator and rotor resistance; $\Delta T_{e 2}^{(k)}$ is torque variation caused by voltage space vector; $T_{s}$ is sampling time; $\sigma$ is constant which is related to $L_{m}, L_{s}$, and $L_{r}$; and $\omega_{r}$ is speed of rotor.

Based on (11), torque ripple is inevitable and influenced by sampling time, motor speed, flux, and voltage vector which are closely related to computing power of digital controller and switching frequency [17]. Therefore, as the external excitation of gear transmission system, torque ripple of electromagnetic torque $T_{e}$ may be higher in actual motor driving process and influence the dynamic characteristics of gear transmission system.

3.2. Modal Property of Multistage Gear Transmission System. In multistage gear transmission system, one-stage pinionring gears consist of several pinions $g_{1}$ and one ring gear $g_{2}$. The size of ring gear $g_{2}$ is much bigger than other gears and the inherent properties of planetary reducer cannot be clearly presented under the influence of ring gear $g_{2}$. Therefore, the modal properties of planetary reducer are chosen to be analyzed in this paper.

Based on (5), equivalent mathematic model of planetary reducer can be expressed in the form of matrix:

$$
M \ddot{q}(t)+C \dot{q}(t)+K q(t)=F(t),
$$

where $q(t)$ is vibration displacement vector; $M$ is mass matrix; $C$ is damping matrix; $K$ is stiffness matrix; and $F(t)$ is excitation vector.

Since the variation range of mesh stiffness is not big, mesh stiffness is simplified as average stiffness. In the same stage, all external mesh stiffness and all internal mesh stiffness are the same separately. The influence of damping is also ignored to obtain the natural frequencies. Thus, the eigenvalue problem of (12) can be expressed as follows:

$$
\omega_{i}^{2} M \varphi_{i}=\bar{K} \varphi_{i}
$$

where $\omega_{i}$ is $i$-order natural frequency; $\bar{K}$ is average stiffness matrix; and $\varphi_{i}$ is $i$-order vibration mode vector as

$$
\begin{gathered}
\varphi_{i}=\left[\phi_{i s}^{(1)}, \phi_{i p 1}^{(1)}, \phi_{i p 2}^{(1)}, \phi_{i p 3}^{(1)}, \phi_{i c}^{(1)}, \phi_{i s}^{(2)}, \phi_{i p 1}^{(2)}, \phi_{i p 2}^{(2)}, \phi_{i p 3}^{(2)}, \phi_{i p 4}^{(2)},\right. \\
\left.\phi_{i c}^{(2)}, \phi_{i s}^{(3)}, \phi_{i p 1}^{(3)}, \phi_{i p 2}^{(3)}, \phi_{i p 3}^{(3)}, \phi_{i p 4}^{(3)}, \phi_{i c}^{(3)}\right] .
\end{gathered}
$$

According to the main parameters of planetary reducer listed in Table 3, natural frequencies and vibration modes can be obtained by solving (13). Natural frequencies are listed in Table 4 and vibration modes are shown in Figure 10. Based on the inherent properties, planetary reducer operates in three types of vibration modes: rigid motion mode, rotational vibration mode, and planet vibration mode. In rigid motion mode, natural frequency $f_{1}=0 \mathrm{~Hz}$ and all components just operate on the basis of transmission ratio without vibration. In rotational vibration mode, natural frequencies $f$ are distinct and $f \neq 0 \mathrm{~Hz}$. All components have rotational vibration and planet gears in each stage operate with the same vibration. In planet vibration mode, natural frequencies $f_{5}=f_{6}=f_{7}=3805 \mathrm{~Hz}, f_{10}=f_{11}=f_{12}=5266 \mathrm{~Hz}$, and $f_{14}=f_{15}=7056 \mathrm{~Hz}$. All central components such as sun gears and planet carriers have no vibration except planet gears.

\subsection{Dynamic Results of Electromechanical Model}

3.3.1. Vibration Displacement. Vibration displacement is one of the most important elements in dynamic response, which denotes the vibration degree of gear transmission system. 


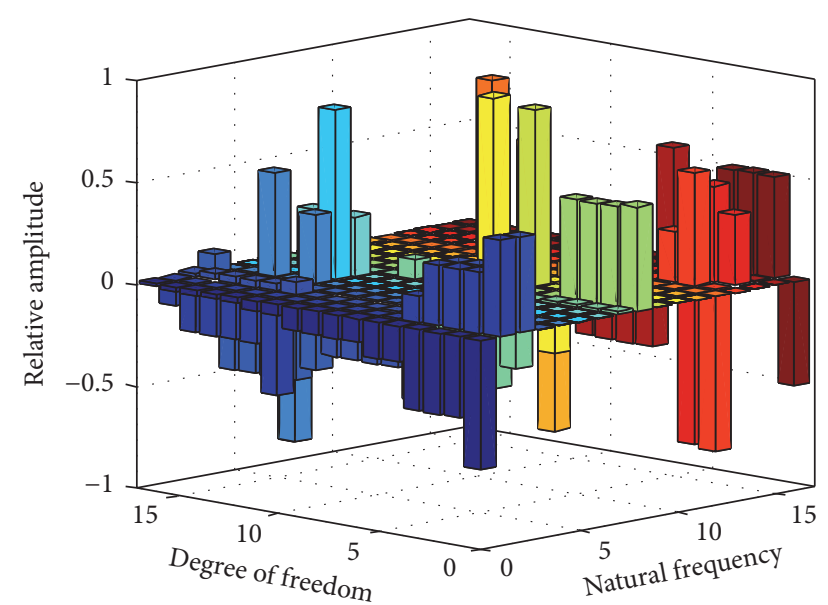

FIGURE 10: Vibration modes of planetary reducer.

Based on the parameters listed in Tables 1, 2, and 3, vibration displacement can be obtained by solving the electromechanical coupling model. As shown and discussed above, torque ripple of inverter motor is unavoidable and may influence the dynamic response of gear transmission system. Therefore, vibration displacements under electromagnetic torque $T_{e}$ with ripple and idealized piecewise torque without ripple are calculated separately.

To ensure the accuracy of results and spare calculation time, Runge-Kutta integration method is chosen to solve the equivalent mathematic model in $1 \mathrm{~s}$. Dynamic responses of sun gears are taken as an example. Vibration displacements of sun gear in each stage are shown in Figure 11. Sun gears vibrate near the equilibrium position and vibration amplitudes decrease as driving torque rises. Vibration amplitude of 2ndstage sun gear is the smallest and significantly smaller than the amplitudes of other sun gears which are approximately equal. Therefore, in the antivibration design process of 3stage gear transmission system in CDS, 1st-stage and 3rdstage gears should be the primary design targets.

For a comparison of dynamic responses under two kinds of driving torque, $\theta_{s e}$ herein is defined as the vibration displacement of sun gear under electromagnetic torque $T_{e}$ and $\theta_{s m}$ herein is defined as the vibration displacement of sun gear under idealized piecewise torque. In the case of 1ststage sun gear for $0.35 \mathrm{~s}$ and $1 \mathrm{~s}$, mean values of $\theta_{\text {se }}$ and $\theta_{s m}$ are the same and equal to 0.0286 , which means that actual driving torque of inverter motor has no effect on equilibrium position. However, standard deviation of $\theta_{s e}$ is 0.0092 and standard deviation of $\theta_{s m}$ is 0.0045 , which indicates that the vibration amplitude under electromagnetic torque $T_{e}$ is bigger than the one under idealized piecewise torque. Thus, it is tempting to conclude that the actual driving torque of inverter motor may aggravate vibration of gear transmission system owing to the torque ripple.

3.3.2. Dynamic Meshing Force. Dynamic meshing force directly influences the failure of gear transmission system such as wear or pitting of gear teeth. Meshing force can be expressed based on (1) as follows:

$$
\begin{aligned}
& F_{s j}^{(i)}=k_{s j}^{(i)} x_{s j}^{(i)}+k c_{s j}^{(i)} \dot{x}_{s j}^{(i)} \\
& F_{r j}^{(i)}=k_{r j}^{(i)} x_{r j}^{(i)}+c_{r j}^{(i)} \dot{x}_{r j}^{(i)},
\end{aligned}
$$

where $F_{s}$ and $F_{r}$ are external/internal meshing forces; $k_{s}$ and $k_{r}$ are time-variant mesh stiffnesses; $x_{s}$ is displacement along the meshing line between the sun gear and each planet gear; and $x_{r}$ is displacement along the meshing line between the ring gear and each planet gear.

Under the external excitation of electromagnetic torque $T_{e}$, dynamic meshing forces in each stage are calculated and a part of them are shown in Figures 13 and 14. In time domain, external meshing forces increase abruptly as electromagnetic torque $T_{e}$ changes at $0.35 \mathrm{~s}$ and meshing forces increase by stage according to gear ratio. Meshing forces of 1st-stage planet gears fluctuate more apparently than the other two stages at changing point which can be probably attributed to the fact that 1st-stage sun gear is directly under the influence of external excitation. In the same stage, meshing forces of planet gears are also different from each other. As shown in Figure 12, load-sharing level of 3rd stage is the highest and load-sharing level of 1st stage is the lowest, which may be caused by phase difference of mesh stiffness and transmission error.

Spectral analysis of external meshing force in each stage is shown in Figure 13. Herein, $f_{n i}(i=2,3)$ donates the $i$-order natural frequency, and $f_{m j}(j=1,2,3)$ donates the $j$-stage mesh frequency. As shown in Figure 13, meshing forces in each stage vibrate in the low frequency domain which is near $f_{m j}$ and its multiple frequencies. Furthermore, low-order natural frequency $\left(f_{n 2}=308, f_{n 3}=529\right)$ also exist in the internal excitations and $f_{n 2}$ possesses the largest amplitude.

\section{Further Discussion}

As shown in Figure 11, vibration of gear transmission system is increased under electromagnetic torque $T_{e}$ compared with idealized driving torque. The increases of vibration on each component may be related to electromagnetic torque $T_{e}$ and its torque ripple. To assess the impact of electromagnetic torque $T_{e}$ on each component's vibration, an influence index $\delta$ of torque ripple is proposed based on the vibration displacements as (16) expresses:

$$
\delta=\frac{A_{e}-A_{m}}{A_{m \max }},
$$

where $A_{e}$ and $A_{m}$ denote the deviation value from equilibrium position under electromagnetic torque $T_{e}$ and idealized torque, respectively; $A_{m \text { max }}$ is the maximum of $A_{m}$ which represents vibration degree; and $A_{e i}$ and $A_{m i}$ can be expressed as follows:

$$
A_{s}=\left|\theta_{s}-\bar{\theta}_{s}\right| \quad(s=e, m),
$$

where $\theta_{s}$ is the vibration displacement of one component under electromagnetic torque $T_{e}$ and idealized torque and $\bar{\theta}_{s}$ is mean value of $\theta_{s}$ which represents equilibrium position. 


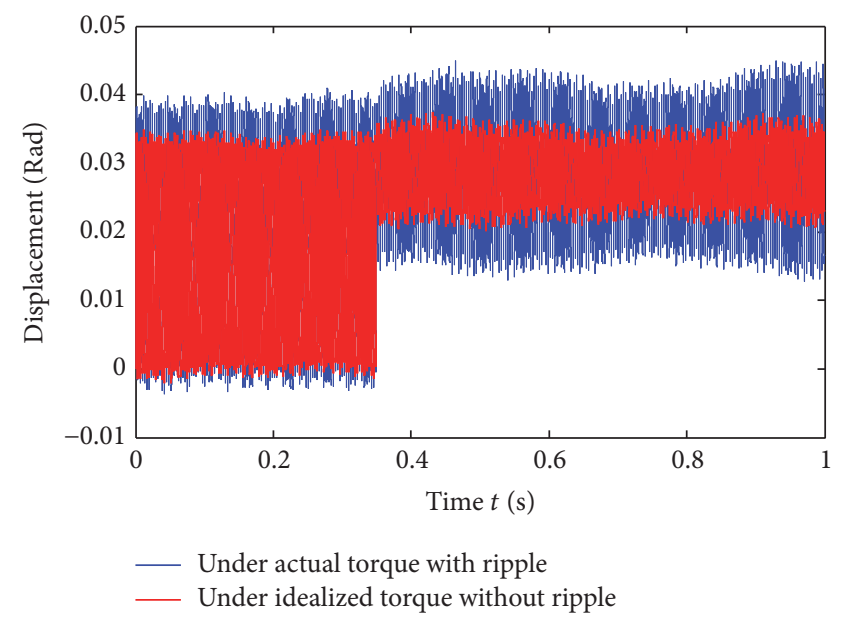

(a) 1st-stage sun gear

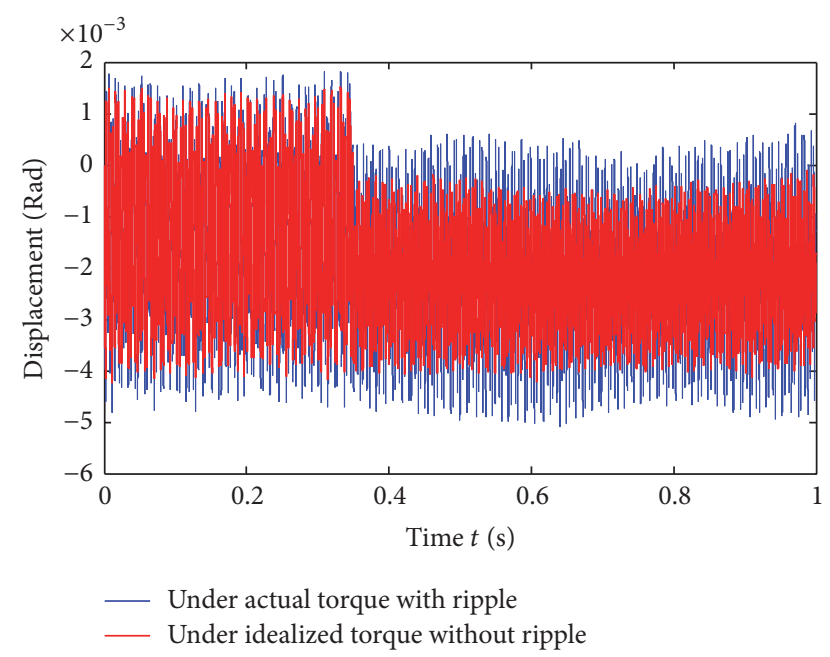

(b) 2nd-stage sun gear

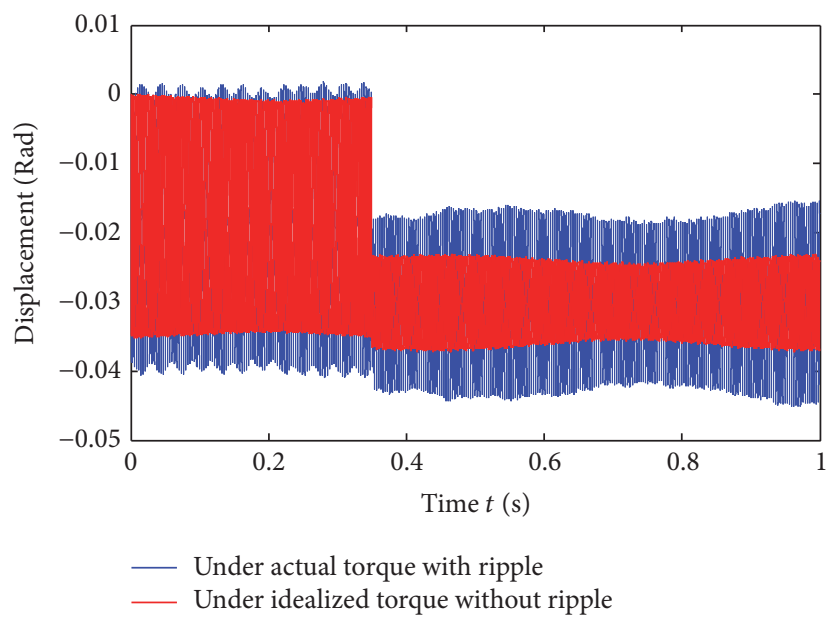

(c) 3rd-stage sun gear

FIGURE 11: Dynamic response of sun gears.

Influence index $\delta$ of torque ripple on all the components is calculated under actual driving torque shown in Figure 9. $\delta$ on different components in the same stage are shown and compared in Figure 14. $\delta$ on the same component in different stages are shown and compared in Figure 15. In time domain, $\delta$ on all the components are greater than zero, which means vibrations of all the components are aggravated by torque ripple of electromagnetic torque $T_{e}$. To each component, $\delta$ increases as load torque $T_{L}$ changes from $1100 \mathrm{~N} \cdot \mathrm{m}$ to $1700 \mathrm{~N} \cdot \mathrm{m}$. In the same stage, $\delta$ on sun gear is the largest and the impact of electromagnetic torque $T_{e}$ on planet carrier is the smallest. In different stages, $\delta$ on sun gear in 2 nd stage is the smallest and the impacts on sun gears in 1st stage and 3rd stage are similar. Thus, as an important performance measure, the influence index $\delta$ on sun gear in 1st stage or 3rd stage can be taken as the optimization objective to minimize the impact of torque ripple.

To study the impact of torque ripple on vibration further, a series of electromagnetic torque $T_{e}$ with different torque ripples are simulated as load torque $T_{L}$ is $1700 \mathrm{~N} \cdot \mathrm{m}$ and dynamic responses under such torques are obtained. Maximum of influence index $\delta_{\max }$ is chosen to represent the overall impact of electromagnetic torque $T_{e}$ with different torque ripples and $\delta_{\max }$ on all components are shown in Figure 16. It can be seen that vibration degrees of all the components are aggravated more severely as torque ripple increases and tendencies of the impact on each component are similar. Therefore, the ripple of electromagnetic torque $T_{e}$ should be controlled to be as small as possible. As shown and discussed above, torque ripple is influenced by several parameters. Since the asynchronous motor is chosen according to the tunneling conditions, parameters of motor are fixed and cannot be adjusted. Thus, in the process of optimizing control method of inverter motor, torque ripple should be reduced by rectifying parameters of speed controller in DTC system. Furthermore, on the premise of meeting tunneling requirements, motor speed can be reasonably controlled to minimize the torque ripple. 


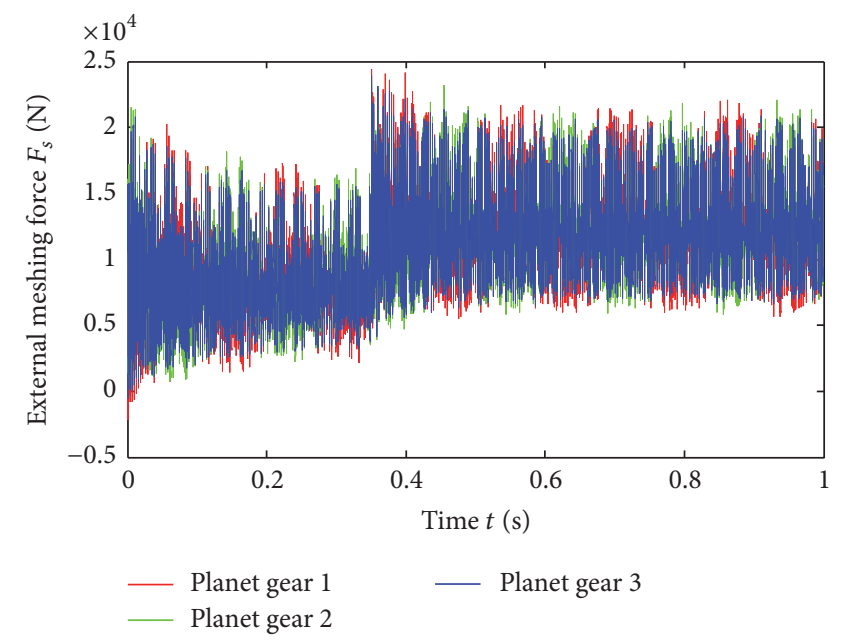

(a) 1st stage

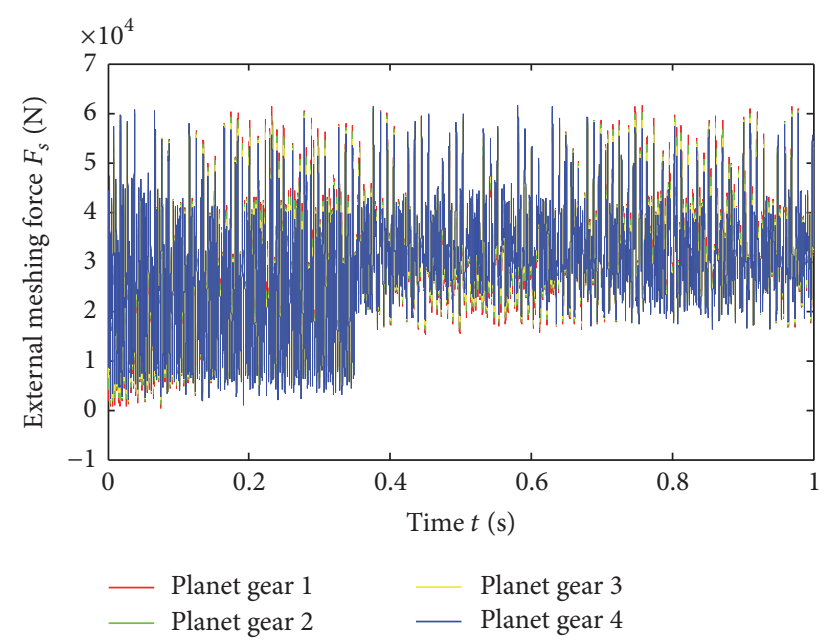

(b) 2nd stage

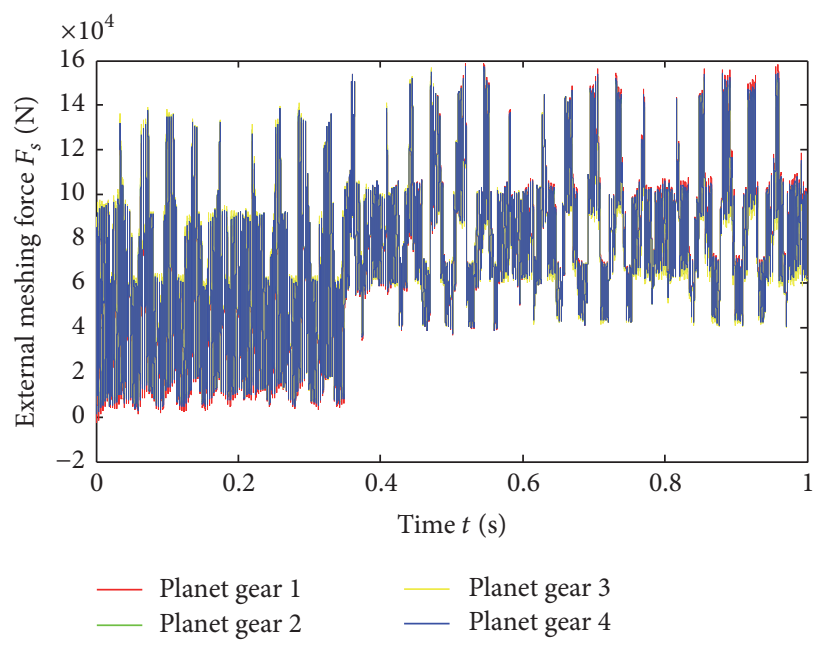

(c) 3rd stage

FIGURE 12: External meshing force in time domain.

\section{Conclusion}

In this paper, an electromechanical coupling model of TBM cutterhead driving system (CDS) is established which includes a simulation model of direct torque control (DTC) driving system and a purely torsional dynamic model of multistage gear transmission system. Based on this coupling model, electromagnetic torque $T_{e}$ is obtained and torque ripple is analyzed. Modal property and dynamic response of gear transmission system are calculated and the impact of torque ripple on vibration is analyzed. The specific conclusions of this study are as follows.

(1) DTC driving system responds quickly as load torque changes and electromagnetic torque $T_{e}$ has high torque ripple which is about $120 \mathrm{~N} \cdot \mathrm{m}$. Torque ripple is influenced by sampling time, motor speed, flux, and voltage vector which are closely related to computing power of digital controller and switching frequency.
(2) Based on the dynamic analysis of gear transmission system, vibration modes of transmission system can be classified into three types: rigid motion mode, rotational vibration mode, and planet vibration mode. For a comparison of vibration displacements, the vibration amplitude of 2 ndstage component is the smallest among all the three stages. Meshing forces mainly vibrate in the low frequency domain which approaches to mesh frequency and low-order natural frequency $\left(f_{2}=308 \mathrm{~Hz}, f_{3}=529 \mathrm{~Hz}\right)$. Moreover, meshing forces increase by stage according to gear ratio and meshing forces of 1st-stage planet gears fluctuate more apparently than the other two stages at changing point of load torque.

(3) Compared with the dynamic responses under idealized piecewise torque, vibration displacements of gear transmission system under electromagnetic torque $T_{e}$ are aggravated owing to the torque ripple. Dynamic index $\delta$ is proposed and discussed to show the impact of electromagnetic torque $T_{e}$. In the same stage, $\delta$ of sun gear is 


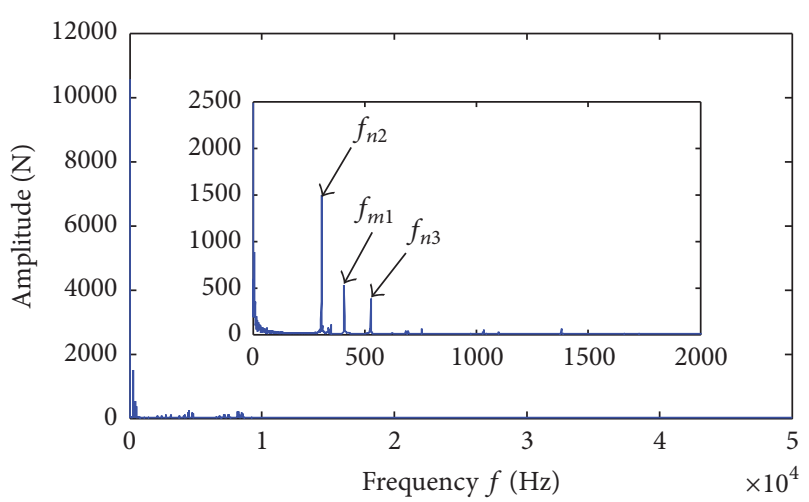

(a) 1st stage

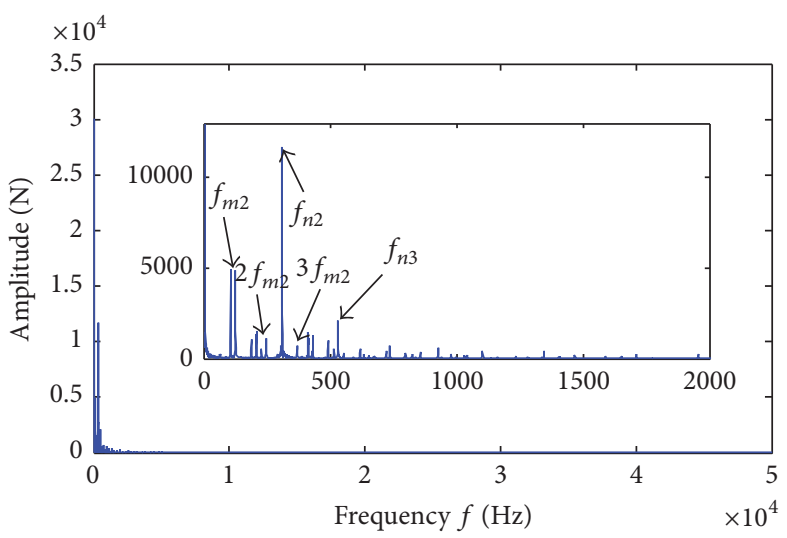

(b) 2nd stage

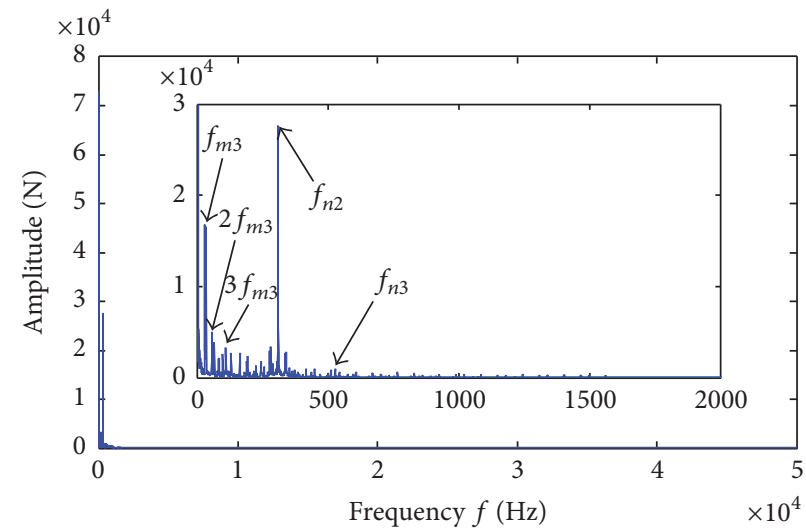

(c) 3rd stage

FIGURE 13: External meshing force in frequency domain.

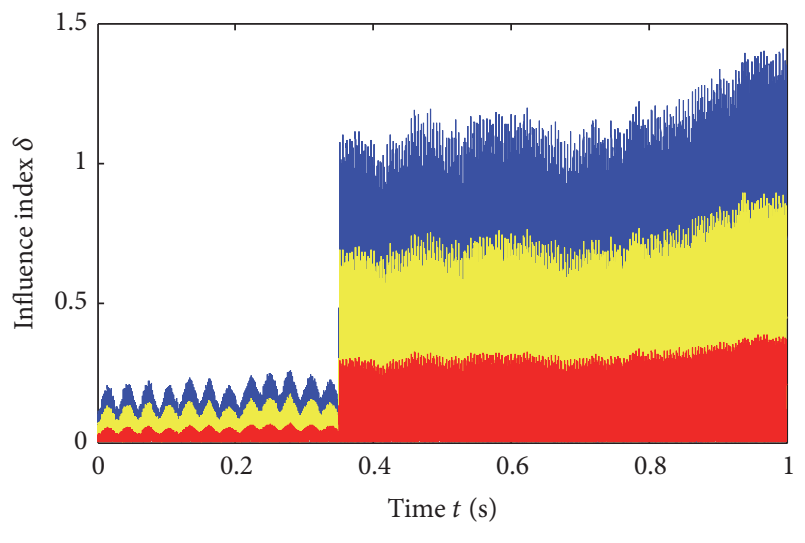

- Sun gear
Planet gear
Planet carrier

Figure 14: Influence index $\delta$ on different components in the 1st stage.

the largest. The impact on 2nd-stage components is the smallest in different stages. Furthermore, vibration degrees of all the components are aggravated more severely as torque

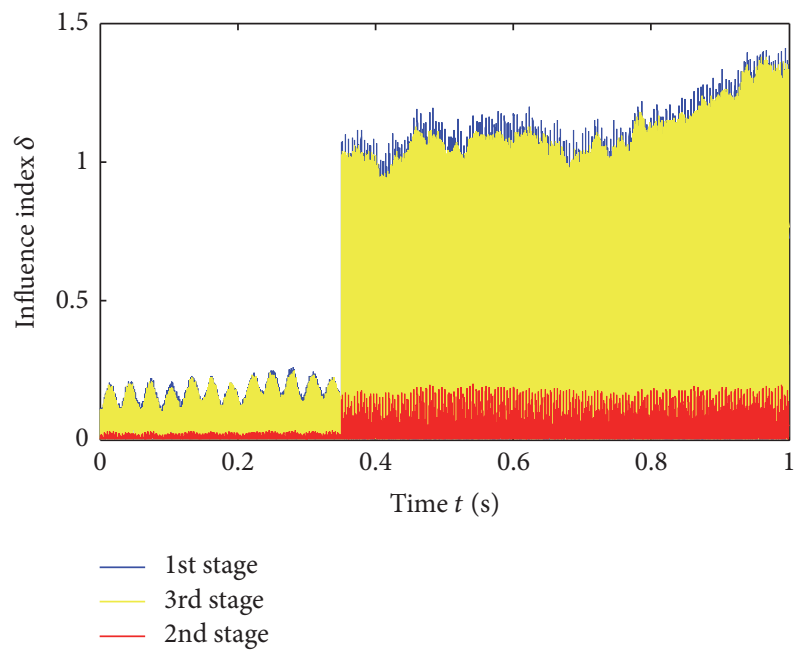

FIGURE 15: Influence index $\delta$ on sun gear in different stages.

ripple increases. Thus, torque ripple should be minimized by optimizing the control method of inverter motor. 


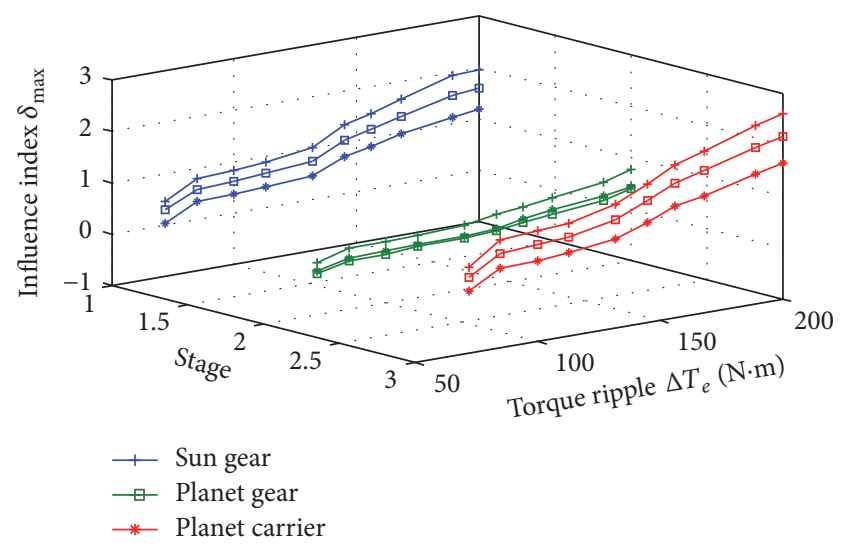

FIGURE 16: Influence index $\delta_{\max }$ under different torque ripples.

\section{Competing Interests}

The authors declare that they have no competing interests.

\section{Acknowledgments}

The National Natural Science Foundation of China (Grant no. 51605071), National Basic Research Program (973 Program) of China (Grant no. 2013CB035400), China Postdoctoral Science Foundation (Grant no. 2015M570245), and Open Foundation of the State Key Laboratory of Fluid Power Transmission and Control of Zhejiang University of China (Grant no. GZKF- 201414) are acknowledged for their financial supports.

\section{References}

[1] W. Sun, J. Ling, J. Huo, L. Guo, X. Zhang, and L. Deng, "Dynamic characteristics study with multidegree-of-freedom coupling in TBM cutterhead system based on complex factors," Mathematical Problems in Engineering, vol. 2013, Article ID 635809, 17 pages, 2013.

[2] A. Delisio, J. Zhao, and H. H. Einstein, "Analysis and prediction of TBM performance in blocky rock conditions at the Lötschberg Base Tunnel," Tunnelling and Underground Space Technology, vol. 33, pp. 131-142, 2013.

[3] A. Kahraman, "Load sharing characteristics of planetary transmissions," Mechanism and Machine Theory, vol. 29, no. 8, pp. 1151-1165, 1994.

[4] J. Huo, H. Wu, G. Li, W. Sun, and J. Chen, "The coupling dynamic analysis and field test of TBM main system under multipoint impact excitation," Shock and Vibration, vol. 2015, Article ID 313259, 14 pages, 2015.

[5] J. Wei, Q. Sun, W. Sun, J. Cai, and J. Zeng, "Dynamic analysis and load-sharing characteristic of multiple pinion drives in tunnel boring machine," Journal of Mechanical Science and Technology, vol. 27, no. 5, pp. 1385-1392, 2013.

[6] J. Wei, Q. Sun, W. Sun, X. Ding, W. Tu, and Q. Wang, "Loadsharing characteristic of multiple pinions driving in tunneling boring machine," Chinese Journal of Mechanical Engineering, vol. 26, no. 3, pp. 532-540, 2013.

[7] W. Sun, X. Ding, J. Wei, X. Wang, and A. Zhang, "Hierarchical modeling method and dynamic characteristics of cutter head driving system in tunneling boring machine," Tunnelling and Underground Space Technology, vol. 52, pp. 99-110, 2016.

[8] K. Zhang, H. Yu, Z. Liu, and X. Lai, "Dynamic characteristic analysis of TBM tunnelling in mixed-face conditions," Simulation Modelling Practice and Theory, vol. 18, no. 7, pp. 1019-1031, 2010.

[9] D. Qin and Y. Zhao, "Multi-objective optimization of multistage planetary gear train used in shield machine cutter driver," China Mechanical Engineering, vol. 23, no. 1, pp. 12-17, 2012.

[10] R. Liu, D. Y. Yu, W. G. Zhao, W. D. Li, and J. Z. Sun, "Research on adaptive load sharing control for multi-motor synchronous driving system of shield machine," Applied Mechanics and Materials, vol. 667, pp. 417-420, 2014.

[11] R. Liu, J. Z. Sun, Y. Q. Luo, W. Sun, and W. D. Li, "Research on multi-motor synchronization control based on the ring coupling strategy for cutterhead driving system of shield machines," Applied Mechanics and Materials, vol. 52-54, pp. 65-72, 2011.

[12] J. Z. Sun, R. Liu, Y. Q. Luo, and W. Sun, "Research on multi-motor synchronization control for cutter head of shield machine based on the ring coupled control strategy," in Intelligent Robotics and Applications, vol. 5928 of Lecture Notes in Computer Science, pp. 345-354, Springer, 2009.

[13] H. Y. Kanaan, K. Al-Haddad, and G. Roy, "Analysis of the electromechanical vibrations in induction motor drives due to the imperfections of the mechanical transmission system," Mathematics and Computers in Simulation, vol. 63, no. 3-5, pp. 421-433, 2003.

[14] R. G. Parker and J. Lin, "Mesh phasing relationships in planetary and epicyclic gears," Journal of Mechanical Design, vol. 126, no. 2, pp. 365-370, 2004.

[15] D. Qin, Z. Xiao, and J. Wang, "Dynamic characteristics of multistage planetary gears of shield tunneling machine based on planet mesh phasing analysis," Journal of Mechanical Engineering, vol. 47, no. 23, pp. 20-29, 2011.

[16] D. Casadei, G. Serra, and A. Tani, "Implementation of a direct torque control algorithm for induction motors based on discrete space vector modulation," IEEE Transactions on Power Electronics, vol. 15, no. 4, pp. 769-777, 2000.

[17] T. Noguchi, M. Yamamoto, S. Kondo, and I. Takahashi, "High frequency switching operation of PWM inverter for direct torque control of induction motor," in Proceedings of the IEEE Industry Applications Conference 32nd IAS Annual Meeting. Part 3 (of 3), pp. 775-780, October 1997. 


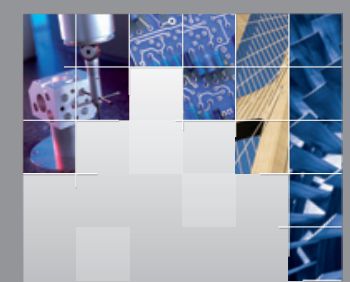

\section{Enfincering}
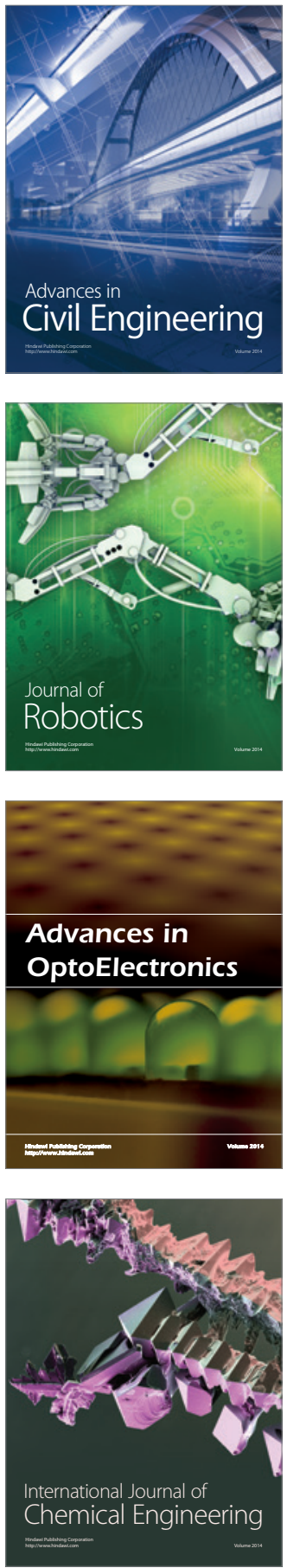

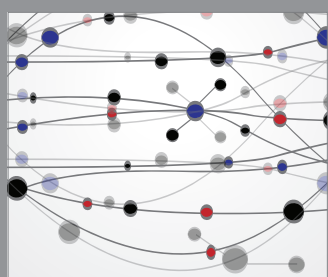

The Scientific World Journal

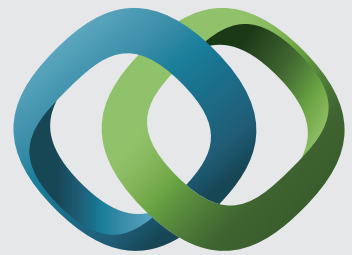

\section{Hindawi}

Submit your manuscripts at

https://www.hindawi.com
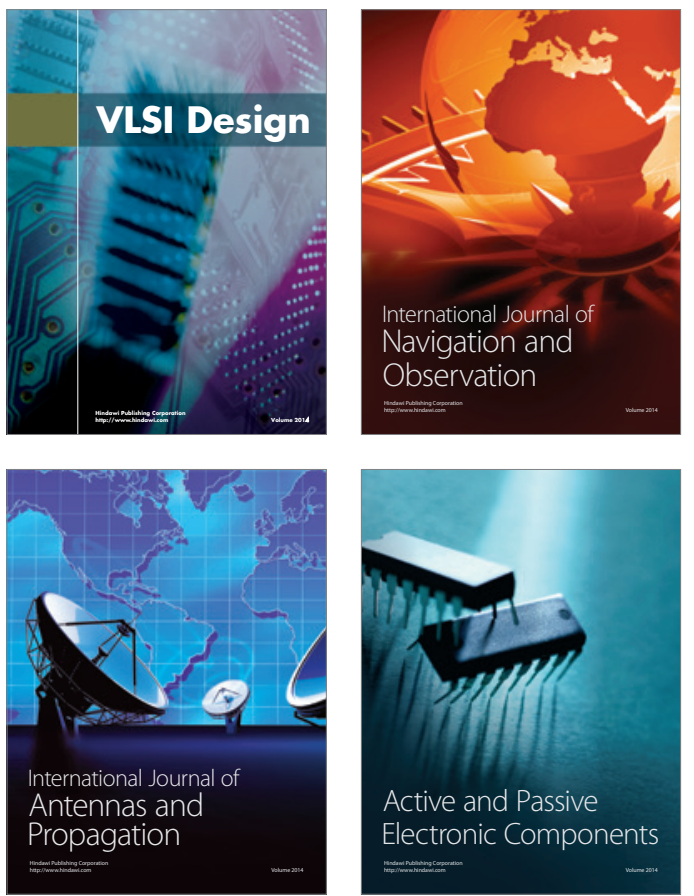
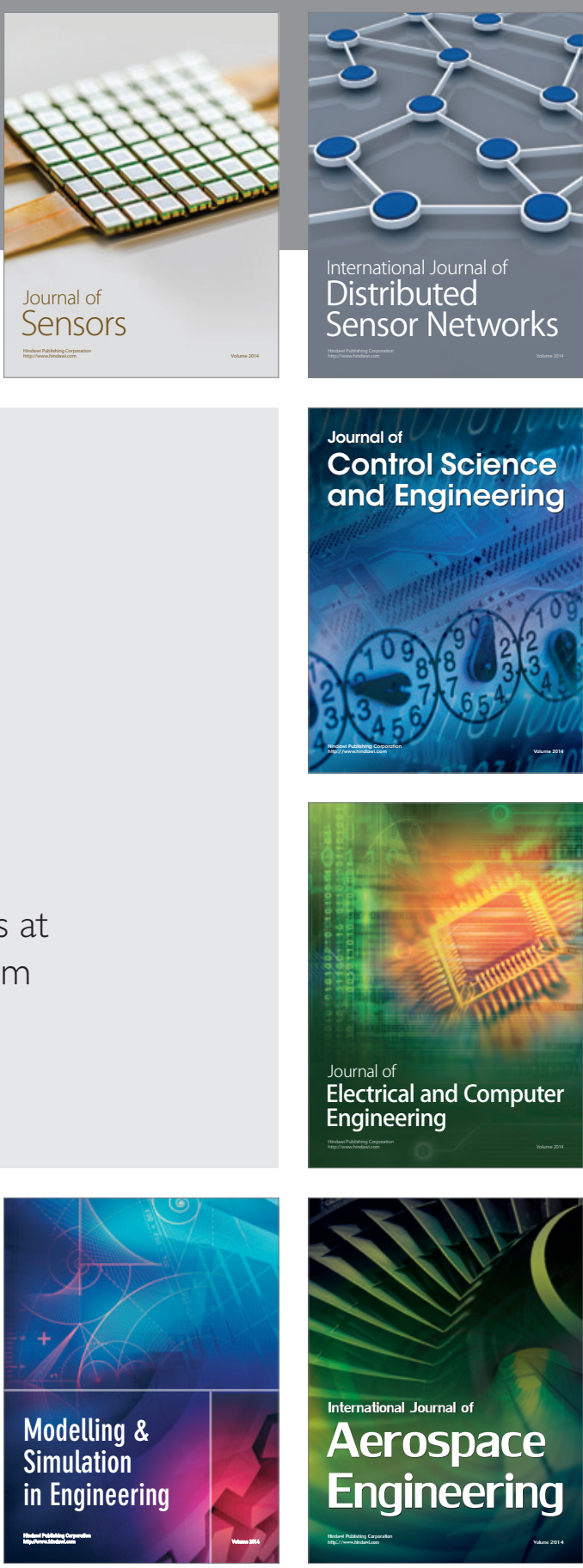

International Journal of

Distributed

Sensor Networks

$-$

Joumal of

Control Science

and Engineering
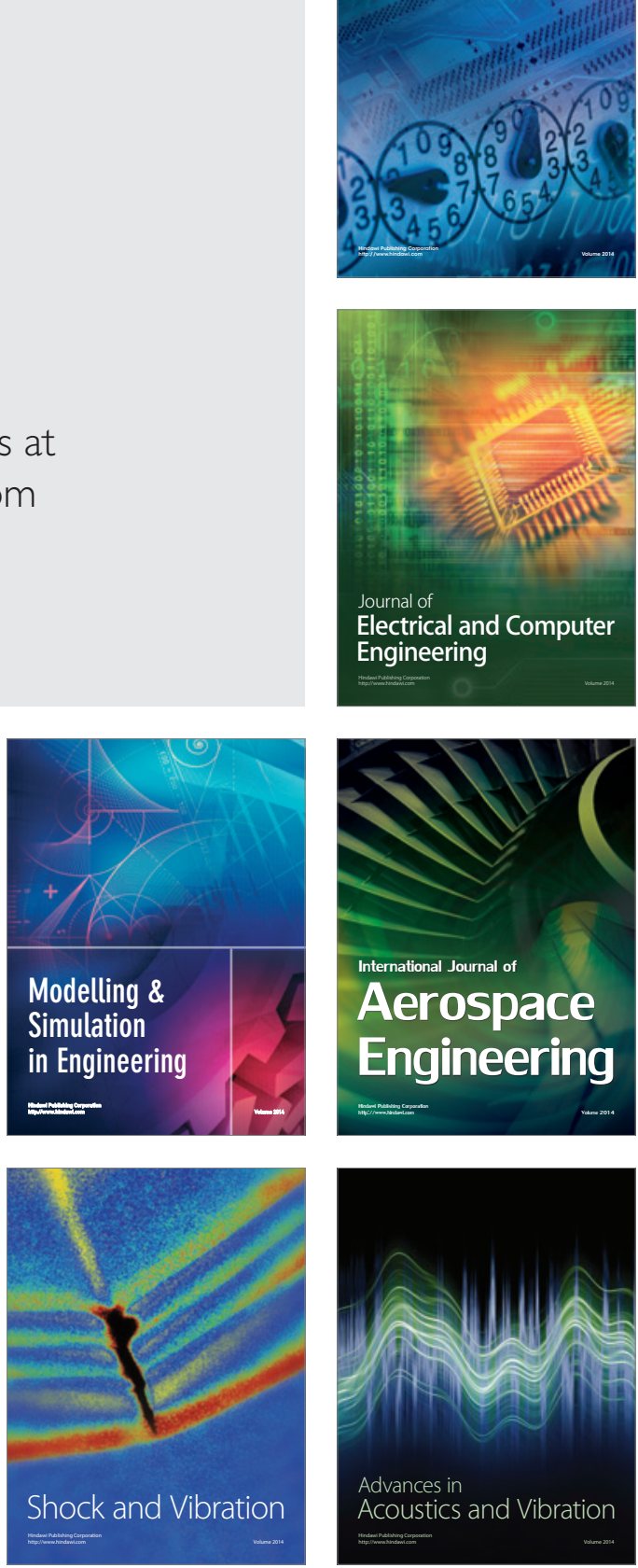